\title{
Calmodulin mutations and life-threatening cardiac arrhythmias: insights from the International Calmodulinopathy Registry
}

\author{
Lia Crotti ${ }^{1,2,3,4,5 *}$, Carla Spazzolini ${ }^{1,5}$, David J. Tester ${ }^{6,7,8}$, Alice Ghidoni ${ }^{1,2,5}$, \\ Alban-Elouen Baruteau ${ }^{5,9,10}$, Britt-Maria Beckmann ${ }^{11}$, Elijah R. Behr ${ }^{5,10}$,
} Jeffrey S. Bennett $\mathbb{1}^{12}$, Connie R. Bezzina ${ }^{5,13}$, Zahurul A. Bhuiyan ${ }^{14}$, Alpay Celiker ${ }^{15}$, Marina Cerrone ${ }^{16}$, Federica Dagradi ${ }^{1,5}$, Gaetano M. De Ferrari ${ }^{17,18}$, Susan P. Etheridge ${ }^{19}$, Meena Fatah ${ }^{20}$, Pablo Garcia-Pavia ${ }^{5,21,22}$, Saleh Al-Ghamdi ${ }^{23}$, Robert M. Hamilton ${ }^{20}$, Zuhair N. Al-Hassnan ${ }^{24}$, Minoru Horie ${ }^{25}{ }^{25}$, Juan Jimenez-Jaimez ${ }^{26}$, Ronald J. Kanter ${ }^{27}$, Juan P. Kaski ${ }^{5,28,29}$, Maria-Christina Kotta ${ }^{1,2,5}$, Najim Lahrouchi ${ }^{5,13}$, Naomasa Makita ${ }^{30}$, Gabrielle Norrish ${ }^{28,29}$, Hans H. Odland ${ }^{31}$, Seiko Ohno ${ }^{25,32}$, John Papagiannis ${ }^{33}$, Gianfranco Parati ${ }^{3,4}$, Nicole Sekarski ${ }^{34}$, Kristian Tveten ${ }^{35}$, Matteo Vatta $^{36,37,38}$, Gregory Webster $^{39}$, Arthur A.M. Wilde ${ }^{5,13}$, Julianne Wojciak ${ }^{40}$, Alfred L. GeorgeJr ${ }^{41}$, Michael J. Ackerman ${ }^{6 * \dagger}$, and Peter J. Schwartz $\mathbb{1}^{1,2,5 * \dagger}$

\footnotetext{
${ }^{1}$ Istituto Auxologico Italiano, IRCCS, Center for Cardiac Arrhythmias of Genetic Origin, Milan, Italy; ${ }^{2}$ Istituto Auxologico Italiano, IRCCS, Laboratory of Cardiovascular Genetics, Milan, Italy; ${ }^{3}$ Istituto Auxologico Italiano, IRCCS, Department of Cardiovascular, Neural and Metabolic Sciences, San Luca Hospital, Milan, Italy; ${ }^{4}$ Department of Medicine and Surgery, University of Milano-Bicocca, Milan, Italy; ${ }^{5}$ Member of the European Reference Network for Rare, Low Prevalence and Complex Diseases of the Heart-ERN GUARDHeart; ' Division of Heart Rhythm Services, Department of Cardiovascular Medicine, Mayo Clinic, Rochester, MN, USA; ${ }^{7}$ Division of Pediatric Cardiology, Department of Pediatric and Adolescent Medicine, Mayo Clinic, Rochester, MN, USA; ${ }^{8}$ Windland Smith Rice Sudden Death Genomics Laboratory, Department of Molecular Pharmacology \& Experimental Therapeutics, Mayo Clinic, Rochester, MN, USA; ${ }^{2}$ 'Institut du Thorax, INSERM, CNRS, UNIV Nantes, CHU Nantes, Nantes, France; ${ }^{10} \mathrm{Cardiology}$ Clinical Academic Group, Molecular and Clinical Sciences Research Institute, St George's University of London, London, UK; ${ }^{11}$ Department of Medicine I, Klinikum Grosshadern, LudwigMaximilians University, Munich, Germany; ${ }^{12}$ The Heart Center, Nationwide Children's Hospital, Columbus, OH, USA; ${ }^{13}$ Amsterdam UMC, University of Amsterdam, Heart Center; Department of Clinical and Experimental Cardiology, Amsterdam Cardiovascular Sciences, Amsterdam, The Netherlands; ${ }^{14}$ Unité de Recherche Cardiogénétique, Service de Médecine Génétique, Lausanne University Hospital (CHUV), Lausanne, Switzerland; ${ }^{15}$ Department of Pediatric Cardiology, Koc University School of Medicine, Istanbul, Turkey; ${ }^{16}$ Cardiovascular Genetics Program, Leon H. Charney Division of Cardiology, New York University School of Medicine, New York, NY, USA; ${ }^{17}$ Division of Cardiology, "Città della Salute e della Scienza di Torino" Hospital, Department of Medical Sciences, University of Turin, Italy; ${ }^{18}$ PhD Program in Translational Medicine, Department of Molecular Medicine, University of Pavia, Pavia, Italy; ${ }^{19}$ Division of Pediatric Cardiology, Department of Pediatrics, University of Utah and Primary Children's Hospital, Salt Lake City, UT, USA; ${ }^{20}$ The Labatt Family Heart Centre and Pediatrics (Cardiology), The Hospital for Sick Children and University of Toronto, Toronto, Ontario, Canada; ${ }^{21}$ Inherited Cardiac Diseases Unit, Department of Cardiology, Hospital Universitario Puerta de Hierro, CIBERCV, Madrid, Spain; ${ }^{22}$ University Francisco de Vitoria (UFV), Pozuelo de Alarcon, Spain, ${ }^{23}$ Cardiac Sciences Department, Section of Pediatric Cardiology, King Abdulaziz Cardiac Center, Ministry of National Guard Health Affairs, Riyadh, Saudi Arabia; ${ }^{24}$ Cardiovascular Genetic Program, Department of Medical Genetics, King Faisal Specialist Hospital and Research Centre, Riyadh, Saudi Arabia; ${ }^{25}$ Department of Cardiovascular and Respiratory Medicine, Shiga University of Medical Science, Otsu, Japan; ${ }^{26}$ Cardiology Department, Virgen de las Nieves University Hospital, Granada, Spain; ${ }^{27}$ Nicklaus Children's Hospital Miami, Miami, FL, USA; ${ }^{28}$ Centre for Inherited Cardiovascular Diseases, Great Ormond Street Hospital, London, UK; ${ }^{29}$ Institute of Cardiovascular Science, University College London, London, UK; ${ }^{30}$ National Cerebral and Cardiovascular Center, Research Institute and Omics Research Center, Osaka, Japan; ${ }^{31}$ Department of Pediatric Cardiology, Oslo University Hospital, Rikshospitalet, Oslo, Norway; ${ }^{32}$ Department of Bioscience and Genetics, National Cerebral and Cardiovascular Center, Osaka, Japan; ${ }^{33}$ Division of Cardiology, Children's Mercy Hospital, Kansas City, MO, USA; ${ }^{34}$ Paediatric Cardiology Unit, Lausanne University Hospital (CHUV), Lausanne, Switzerland; ${ }^{35}$ Department of Medical Genetics, Telemark Hospital Trust, Skien, Norway; ${ }^{36}$ Department of Medical and Molecular Genetics, Indiana University School of Medicine, Indianapolis, IN, USA; ${ }^{37}$ Department of Medicine, Indiana University School of Medicine, Indianapolis, IN, USA; ${ }^{38}$ Invitae Corporation, San Francisco, CA, USA; ${ }^{39}$ Division of Cardiology, Ann and Robert H. Lurie Children's Hospital of Chicago, Northwestern University Feinberg School of Medicine, Chicago, IL, USA; ${ }^{40}$ Department of Genomic Medicine, University of California San Francisco (UCSF), San Francisco, CA, USA; and ${ }^{41}$ Department of Pharmacology, Northwestern University Feinberg School of Medicine, Chicago, IL, USA
}

* Corresponding author. Tel: +3902 55000408, Fax: +3902 55000411, Email: peter.schwartz@unipv.it, p.schwartz@auxologico.it; Tel: +39 02 619112374, Fax: +39 02 619112956, Email: I.crotti@auxologico.it; Tel: +1 507284 0101, Fax: +1 507284 3757, Email: ackerman.michael@mayo.edu

tThe last two authors are co-equal senior authors.

Published on behalf of the European Society of Cardiology. All rights reserved. (c) The Author(s) 2019. For permissions, please email: journals.permissions@oup.com. 
Aims

Methods and results

\section{Conclusion}

Keywords
Calmodulinopathies are rare life-threatening arrhythmia syndromes which affect mostly young individuals and are, caused by mutations in any of the three genes (CALM 1-3) that encode identical calmodulin proteins. We established the International Calmodulinopathy Registry (ICalmR) to understand the natural history, clinical features, and response to therapy of patients with a CALM-mediated arrhythmia syndrome.

A dedicated Case Report File was created to collect demographic, clinical, and genetic information. ICalmR has enrolled 74 subjects, with a variant in the CALM1 $(n=36)$, CALM2 $(n=23)$, or CALM3 $(n=15)$ genes. Sixty-four (86.5\%) were symptomatic and the 10 -year cumulative mortality was $27 \%$. The two prevalent phenotypes are long QT syndrome (LQTS; CALM-LQTS, $n=36,49 \%$ ) and catecholaminergic polymorphic ventricular tachycardia (CPVT; CALM-CPVT, $n=21,28 \%$ ). CALM-LQTS patients have extremely prolonged QTc intervals $(594 \pm 73 \mathrm{~ms})$, high prevalence (78\%) of life-threatening arrhythmias with median age at onset of 1.5 years [interquartile range (IQR) 0.1-5.5 years] and poor response to therapies. Most electrocardiograms (ECGs) show late onset peaked T waves. All CALM-CPVT patients were symptomatic with median age of onset of 6.0years (IQR 3.0-8.5 years). Basal ECG frequently shows prominent $U$ waves. Other CALM-related phenotypes are idiopathic ventricular fibrillation (IVF, $n=7)$, sudden unexplained death (SUD, $n=4)$, overlapping features of CPVT/LQTS $(n=3)$, and predominant neurological phenotype $(n=1)$. Cardiac structural abnormalities and neurological features were present in 18 and 13 patients, respectively.

Calmodulinopathies are largely characterized by adrenergically-induced life-threatening arrhythmias. Available therapies are disquietingly insufficient, especially in CALM-LQTS. Combination therapy with drugs, sympathectomy, and devices should be considered.

Calmodulin - Cathecolaminergic polymorphic ventricular tachycardia - Idiopathic ventricular fibrillation

- Long QT syndrome • Sudden death

\section{Introduction}

A severe form of long QT syndrome (LQTS) with early occurrence of life-threatening arrhythmias caused by mutations in one of the three genes (CALM 1-3) encoding calmodulin (CaM) was first reported in 2013. ${ }^{1} \mathrm{CaM}$ is a ubiquitous, multifunctional $\mathrm{Ca}^{2+}$ binding protein. The clinical presentation was similar among the affected individuals, including a markedly prolonged QTc, episodes of $T$ wave alternans, 2:1 functional atrioventricular block, cardiac arrest in the first year(s) of life, and need for an implantable cardioverter-defibrillator (ICD) despite optimal medical therapy. Since then, scattered reports on few patients and isolated families emerged. ${ }^{2-13}$ The phenotype most frequently shown by patients with CALM mutations was LQTS, ${ }^{1,4-8,12}$ but some had catecholaminergic polymorphic ventricular tachycardia $(\mathrm{CPVT})^{2,10}$ or idiopathic ventricular fibrillation (IVF). ${ }^{3}$ CALM mutations were also identified in autopsy-negative sudden unexplained deaths (SUD) in young individuals. ${ }^{9}$ Given the wide spectrum of the clinical manifestations associated to CALM mutations, the term 'Calmodulinopathy' was coined. ${ }^{14}$

Given the apparent rarity and lethality of the CALM-mediated arrhythmogenic diseases, with a heterogeneous genetic background and variable clinical phenotype, we thought that an international cooperative effort was the only feasible way to begin to understand the natural history, clinical features, and response to therapy of these patients. As done 40 years ago for LQTS, ${ }^{15-17}$ we (L.C., P.J.S., and M.J.A.) established the International Calmodulinopathy Registry (ICalmR) and here we report the initial findings.

\section{Methods}

\section{Subjects and ascertainment}

The study population $(n=74)$ comes from two sources, the International Calmodulinopathy Registry (ICalmR) and the published literature. The ICalmR is a worldwide multicentre clinical observational Registry established in 2015 with the goal of recruiting patients with a pathogenic variant in the CALM1, CALM2, or CALM3 genes regardless of the phenotype (LQTS, CPVT, IVF, other). To enroll patients, we have involved most of the centres and key investigators expert in arrhythmic diseases of genetic origin and having published the first description of CALM-LQTS patients, we have also been contacted by investigators who had encountered even a single case. Including the two co-ordinating centres (Istituto Auxologico Italiano IRCCS, Milan, Italy, and Mayo Clinic, Rochester, MN, USA), 22 centres from Europe, North America, and Asia have joined the Registry by contributing 58 (78\%) genotyped patients with CALM-mediated arrhythmia syndromes. A dedicated Case Report File was created to collect demographic, clinical, and genetic information. The Ethics Committees of the co-ordinating and enrolling centres approved the study. The patient data were released in an anonymous form.

We used published literature as an additional source of 16 cases (22\%), for whom high quality clinical and genetic details were available. In total, here, we report data on 74 patients with a calmodulinopathy.

\section{Genetic characterization}

The pathogenic/likely pathogenic CALM variants included in the Registry were identified through whole exome sequencing (WES), targeted nextgeneration sequencing (NGS), or Sanger sequencing, in 51\%, $29 \%$, and $20 \%$ of the index patients, respectively. None of the patients enrolled had additional clinically relevant pathogenic variants in other arrhythmiasusceptibility genes. 
The nomenclature of the reported genetic variants conforms to the latest Human Genome Variation Society guidelines. ${ }^{18}$ We specifically numbered amino acid positions based on assignment of the initiating methionine start codon as position 1. The CALM acronym refers to any of the three calmodulin genes, while the CaM acronym refers to the calmodulin protein. Variant classifications were made according to the American College of Medical Genetics Guidelines (ACMG). ${ }^{19}$ Genetic variants were specifically analysed focusing on: presence or absence in publicly available exome/genome databases (1000 Genomes, Exome Variant Server, ExAC, gnomAD), ${ }^{20-22}$ amino acid conservation across species (in 100 vertebrates), protein domain affected by the amino acid change, previous literature description and functional characterization.

\section{Phenotype characterization}

The data of each enrolled patient included demographics, personal and family histories, foetal-perinatal period information, comorbidities, electrocardiogram (ECG) parameters, individual phenotypic features, cardiac events information, therapies. Based on phenotype and clinical judgement, the patients were classified with one of the following major conditions: LQTS, ${ }^{23} \mathrm{CPVT}^{24}{ }^{24}$ IVF, ${ }^{24}$ overlap between LQTS/CPVT, and SUD in young individuals. LQTS and CPVT were the two most prevalent subgroups, henceforth referred to as CALM-LQTS and CALM-CPVT. Idiopathic ventricular fibrillation is defined as a resuscitated cardiac arrest victim, preferably with documentation of ventricular fibrillation (VF), in whom known cardiac, respiratory, metabolic and toxicological aetiologies have been excluded through clinical evaluation. ${ }^{23}$ SUD is defined as a natural, unexpected fatal event occurring within $1 \mathrm{~h}$ from the onset of symptoms in an apparently healthy subject, with no known familial disease. In all SUD cases, an autopsy was performed and obvious causes were excluded; no ECG was available in these cases, and only molecular autopsy allowed the diagnosis of calmodulinopathy.

Subjects were considered symptomatic if they suffered at least one cardiac event, such as syncope (fainting spell with transient, but complete, loss of consciousness), aborted cardiac arrest (ACA) requiring resuscitation, or sudden cardiac death (SCD) occurring before age 20. Seven firstdegree relatives of three probands who died before diagnosis, in the absence of genetic testing, were assumed to be positive for the same CALM variant identified in their family and were consequently included. One patient, with marked neonatal sinus bradycardia and a cardiogenic shock soon after birth, was considered as symptomatic. Appropriate ICD discharges for ventricular tachycardia (VT)/NF were counted and considered together with ACA and SCD as major arrhythmic events (MAEs). A perinatal presentation was defined as the occurrence of symptoms in the period ranging from approximately the 28 th week of gestation to the 28th day after birth.

\section{Statistical analysis}

Continuous data are presented as mean and standard deviation or as median and interquartile range (IQR, 25th-75th percentile), and analysed with the Student's $t$-test or with the Mann-Whitney test. Categorical variables were presented as absolute (n) and relative frequencies (\%), and compared among phenotype groups with the Fisher's exact test or $\chi^{2}$ test as appropriate. Event-free survival is described by Kaplan-Meier cumulative estimates, with the comparison between subgroups performed by the log-rank test. Two-sided $P$-values $<0.05$ were considered statistically significant. SPSS Statistics version 23 (IBM Co, Armonk, NY, USA) was used for computation.

\section{Results}

\section{Registry population}

The ICalmR has enrolled 74 subjects with a pathogenic or likely pathogenic variant in either CALM1, CALM2, or CALM3 from 51 different families.

\section{Genetic features}

Thirty-five single nucleotide substitutions leading to 28 distinct amino acid changes were identified in the 74 CALM-positive patients (36 CALM1, 23 CALM2, and 15 CALM3 patients) included in the Registry. Among these 35 variants, 11 (31\%) were in CALM1, 16 (46\%) in CALM2, and 8 (23\%) in CALM3. These genetic variants are schematically depicted in Figure 1 and summarized in Supplementary material online, Table S1. They constitute a homogeneous group of missense variants with recurrent and similar features. Specifically, amino acid changes always involved highly conserved residues (degree of conservation among 100 vertebrates $\geq 99 \%$ ), all were classified as pathogenic/likely pathogenic ${ }^{19}$ and none were present in publicly available exome/genome databases including more than 140000 individuals (accessed September 2018). ${ }^{20-22}$

The majority of variants affected amino acid residues in the EFhand $\mathrm{Ca}^{2+}$ binding loop III and IV [28/35 nucleotide substitutions (80\%)], and most of them affected one of the four amino acid residues principally involved in $\mathrm{Ca}^{2+}$ binding (Asp, Asp, Asp/Asn, and Glu, at positions 1, 3, 5, and 12, respectively, from the beginning of each 12-residue loop) [25/28 nucleotide substitutions (89\%)]. Interestingly, while most of the variants were unique by type and gene location, nine were present in more than one index case and among these, three (p.Asn98Ser, p.Asp130Gly, and p.Phe142Leu) appeared to be relative hot-spots, identified in 10, 5, and 4 families, respectively. Of note, while p.Asp130Gly and p.Phe142Leu were always associated with the LQTS phenotype, the p.Asn98Ser had phenotypic variability, including LQTS, CPVT, IVF, and SUD. Despite the relatively small numbers of cases, a significant association $(P=0.001)$ was observed between location of mutation and phenotype (Supplementary material online, Figure S1). Indeed, a pathogenic variant in EF-hand IV Ca ${ }^{2+}$ binding loop was found in the majority (17/32, 53\%) of CALM-LQTS index cases but in only one of the nine CALM-CPVTs (11\%). Conversely, variants identified in CALM-CPVT index cases were mostly located either in EF-hand III ( $n=5,56 \%)$, or in the inter-EF hand I-II linker $(n=3,33 \%)$.

In 27/29 (93\%) CALM-LQTS and in 7/9 CALM-CPVT (78\%) patients whose family members were genetically screened, the culprit variant was de novo. In the remaining two CALM-LQTS cases and in one IVF case, germline mosaicism was present in one of the parents.

Interrogation of the gnomAD database ${ }^{22}$ (September 2018) for variants in the three main transcripts of the calmodulin genes revealed a much lower than expected number of missense and lossof-function variants, indicating that the CALM genes are intolerant to such variations, while they result more tolerant to synonymous variation, as indicated by the relative constraint metrics (i.e. statistics based on observed/expected variant comparisons). Among the exonic non-synonymous variants reported in the gnomAD datasets $(n=29),{ }^{22} 21$ were located outside the EF-hand loops, and none of the remaining 8 involved the principal $\mathrm{Ca}^{2+}$ binding residues. 


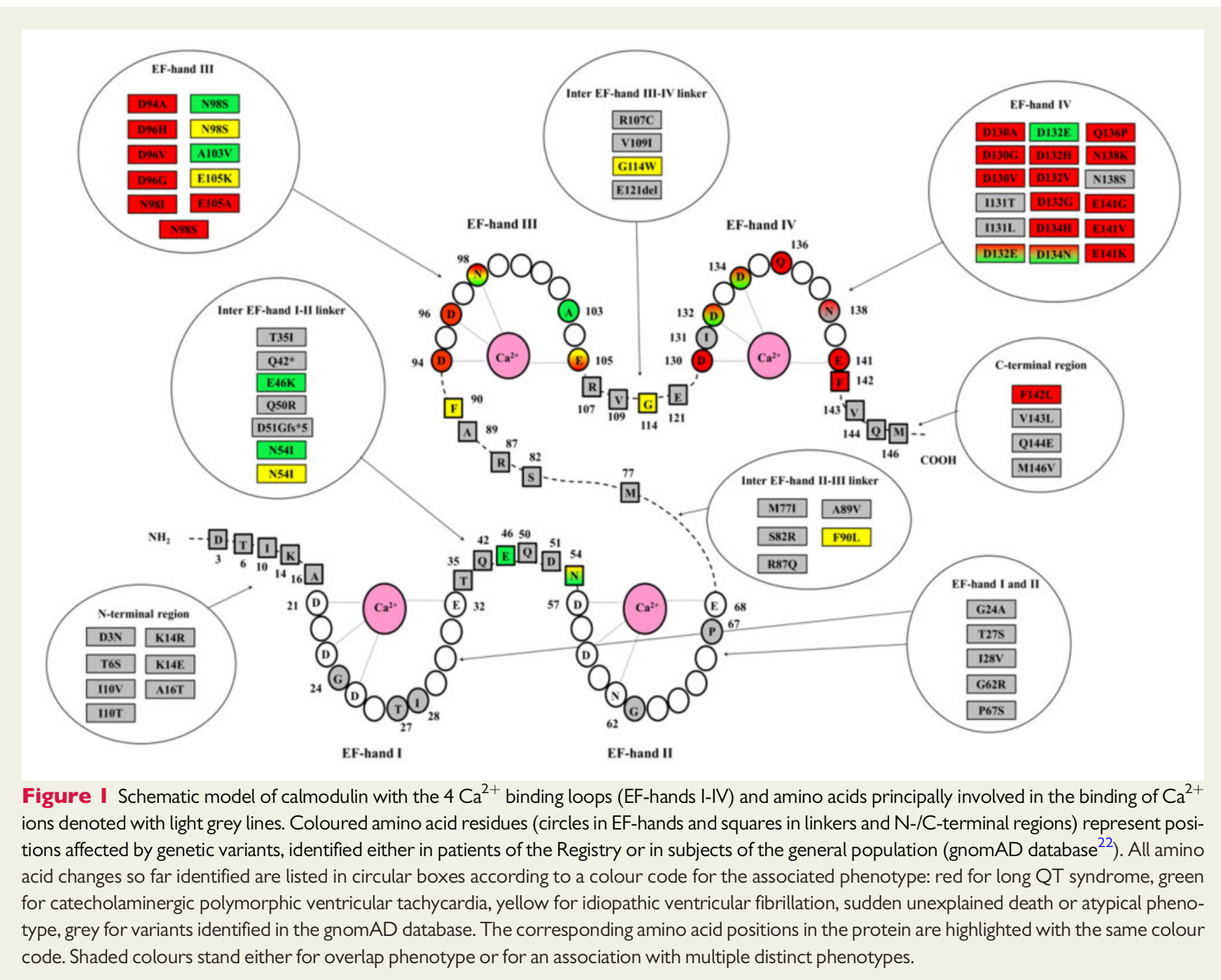

Therefore, the presence of genetic variants within the EF-hand $\mathrm{Ca}^{2+}$ binding loops differs significantly between index cases of the Registry and the general population ( $80 \%$ vs. $28 \%, P<0.0001)$. The different location of variants in our cases and in the general population is shown in Figure 1.

\section{General clinical features}

The clinical characteristics of the study population [ $51 \%$ males, median age 9.0years (IQR 4.5-15.0)] are summarized in Table 1. The ethnic-geographic background was heterogeneous with $55 \%$ of subjects having European ancestry. Most patients $(n=64,86.5 \%)$ were symptomatic and, by age $5,50 \%$ had already experienced an arrhythmic event (Figure 2A). Males had a significantly higher probability of becoming symptomatic than females $(P=0.02$; Figure $2 B)$. Triggers of cardiac events were adrenergic stimuli in $81 \%$ of patients, irrespective of the phenotype and mostly (62\%) associated with exertion. Major arrhythmic events (ACA, SCD/SUD, ICD appropriate discharges) occurred in $50(68 \%)$ subjects at a median age at first event of 5.0 years (IQR 2.0-10.0). Twenty (27\%) had SCD at a mean age of $5.7 \pm 4.6$ years [median 4.8, IQR (1.6-9.8)]. As shown in Figure 2C, the
2-, 5-, and 10-year cumulative survival was $88 \%, 84 \%$, and $73 \%$, respectively. Three children with CALM-LQTS diagnosed in the neonatal period died a non-arrhythmic death, at 8 days, 6 months, and 5 years, due to ICD implant complications, heart failure and infection post-cardiac surgery, and hypoglycaemia, respectively.

The two most prevalent phenotypes were LQTS $(n=36)$ and CPVT $(n=21)$, observed in $77 \%$ of the entire study population (Table 2).

\section{CALM-LQTS}

The thirty-six CALM-LQTS patients (49\% of total cohort) exhibited an extremely prolonged mean QTc $(594 \pm 73 \mathrm{~ms})$ and a high prevalence $(78 \%)$ of life-threatening arrhythmias occurring very early in life. There were $10 \mathrm{SCD}$, mostly before age 3 . In addition to the marked QT interval prolongation, a typical repolarization morphology, characterized by a late onset peaked $T$ wave, was observed in 19/23 (83\%) CALM-LQTS patients. This ECG pattern resembles that of LQT3 and Timothy Syndrome (Supplementary material online, Figure S2). However, at variance with LQT3, ${ }^{25}$ only in one of the six CALM-LQTS cases acute oral mexiletine significantly shortened QTc. 
Table I International Calmodulinopathy Registry

\begin{tabular}{|c|c|}
\hline \multicolumn{2}{|l|}{ Demographic and clinical characteristics } \\
\hline Patients, $n$ & 74 \\
\hline Families, $n$ & 51 \\
\hline Males, $n(\%)$ & $38(51)$ \\
\hline Age at last follow-up (years), median (IQR) & $9.0(4.5-15.0)$ \\
\hline \multicolumn{2}{|l|}{ Population/Ethnicity, $n(\%)^{\mathrm{a}}$} \\
\hline European/European American & $40(55)$ \\
\hline Latino & $3(4)$ \\
\hline East Asian (Japan) & $8(11)$ \\
\hline South Asian (India) & $4(5)$ \\
\hline African/African American & $2(3)$ \\
\hline Others & $16(22)$ \\
\hline \multicolumn{2}{|l|}{ Symptomatic, $n(\%)$} \\
\hline Any cardiac event & $64(86.5)$ \\
\hline$M A E^{b}$ & $50(68)$ \\
\hline SUD/SCD & $20(27)$ \\
\hline Age at first event (years), median (IQR) & $4.0(1.5-8.0)$ \\
\hline \multicolumn{2}{|l|}{ Any treatment prescribed $(n=69)$} \\
\hline No therapy & $13(19)$ \\
\hline$\beta$-blockers, $n(\%)$ & $54(78)$ \\
\hline Sodium channel blockers, $n(\%)$ & $21(30)$ \\
\hline Other antiarrhythmic drugs (verapamil, nicorandil) & $4(6)$ \\
\hline $\mathrm{LCSD} / \mathrm{RCSD},{ }^{\mathrm{c}} n(\%)$ & $4(6)$ \\
\hline Implantable devices & $32(46)$ \\
\hline Pacemaker, $n(\%)$ & $7(10)$ \\
\hline ICD, $n(\%)$ & $25(36)$ \\
\hline Events on therapy ( $n=54$ with known data) & $29(54)$ \\
\hline Appropriate ICD discharges, $n(\%)$ & $16(30)$ \\
\hline $\mathrm{SCD}, n(\%)$ & $8(15)$ \\
\hline
\end{tabular}

'Patients' ethnicity was presented according to the population subgroups proposed in ExAC/gnomAD databases. ${ }^{22}$ For one patient, ethnicity was not reported.

${ }^{\mathrm{b}} \mathrm{ACA}, \mathrm{SUD} / \mathrm{SCD}$, VF detected/treated by ICD.

'One patient underwent both procedures, the remaining three only LCSD.

The onset of spontaneous major arrhythmias was recorded only in seven cases: it was always an abrupt onset of VF, while a pausedependent TdP was never observed (Figure 3C). In 58\% of CALMLQTS patients there was a perinatal presentation, consisting in a variable combination of striking QT prolongation (QTc $628 \pm 62 \mathrm{~ms}$ ), sinus bradycardia, 2:1 atrioventricular block (Figure 3A), $T$ wave alternans $^{25}$ (Figure 3B), and/or MAEs (Figure 3C). This early onset was almost exclusive of the LQTS phenotype (91\%) (Supplementary material online, Table S2). Among CALM-LQTS patients, 13 (41\%) also had cardiac structural abnormalities (Table 2, Supplementary material online, Table S3).

\section{CALM-CPVT}

All 21 CALM-CPVT patients (13 from a single large family) were symptomatic for adrenergically-induced cardiac events (10 with MAEs) starting in childhood, with CPVT-like features of stress testinduced ventricular ectopies, ranging from isolated premature ventricular contractions to non-sustained ventricular tachycardia and
VT/VF (Supplementary material online, Figure S3). Ectopic beats were most often reported as polymorphic and rarely and inconsistently as truly bidirectional. Only one patient showed perinatal onset with severe foetal bradycardia $\leq 90$ b.p.m. at 28 weeks gestational age (Supplementary material online, Table S2). In comparison with CALMLQTS, CALM-CPVT patients were older at onset (median age 6 vs. 1.5 years, $P=0.005$ ) and had fewer MAEs (48\% vs. 78\%, $P=0.04$ ), with sudden death occurring in $14 \%$ of them (Table 2). Two unrelated subjects, with the same CALM mutation, had a patent ductus arteriosus as associated cardiac abnormality (Supplementary material online, Table S3). In six of the eight available baseline ECGs, a prominent $U$ wave was observed in few precordial leads, with a repolarization pattern similar to what observed in Andersen-Tawil Syndrome ${ }^{26}$ (Supplementary material online, Figure S4).

\section{Other phenotypes}

The other phenotypes observed in association to CALM mutations were IVF $(n=7)$, SUD $(n=4)$, overlap CPVT/LQTS $(n=3)$, and an atypical cardio-neurological phenotype $(n=1)$. Only two subjects, part of an IVF family, remain completely asymptomatic at age 14 and 60, and with a normal ECG. SUD, IVF (Supplementary material online, Figure S5), and overlapping phenotypes frequently show adrenergicallyinduced ventricular arrhythmias and cardiac events. One patient, with a borderline QTc and peaked T waves, had recurrent neurologicallymediated seizures since age 3; cardiac events concomitant with seizures were excluded by an implantable loop recorder (ILR).

\section{Neurological features in CALM-positive subjects}

For 13 subjects, most with an LQTS phenotype $(n=10)$ and a CALM1 mutation $(n=9)$, a mild-to-severe neurological impairment was reported, including seizures, development delay, motor and/or cognitive disability. In seven young patients, the neurologic deficits were observed following ACA, and therefore, these deficits are likely postanoxic sequelae; six of them improved gradually during follow-up. In the six remaining patients, neurological features were unrelated to cardiac arrests and ranged from mental retardation and developmental delay to recurrent seizures and autism.

\section{Treatment and outcome}

Data on therapy were known for 69 of the 74 patients (Table 1); for five patients that originated from published literature, precise information on therapy was unavailable and could not be retrieved. Thirteen were never treated, 54 (78\%) were treated with $\beta$-blockers, 21 (30\%) with a sodium channel blocker (mexiletine, flecainide, or ranolazine), 3 patients received verapamil, 1 nicorandil, and 4 (6\%) underwent left cardiac sympathetic denervation (LCSD). In addition to 2 ILRs, 32 patients (46\%) received a therapeutic device [(pacemaker, PM, $n=7$ ), $\operatorname{ICD}(n=25)]$ with a median age at first implant of 2 year (IQR 0-9.5).

In the two larger phenotypic groups (CALM-LQTS and CALMCPVT), therapeutic attempts largely met with failure, as suggested by a global $56 \%$ prevalence of patients with cardiac events recurring despite $\beta$-blockers, sodium channel blockers, other antiarrhythmics, and LCSD. All these patients $(n=45)$ with available data on treatment received $\beta$-blockers, either alone $(n=15)$ or in combination with other therapies $(n=30)$, either as concomitant or subsequent therapeutic 


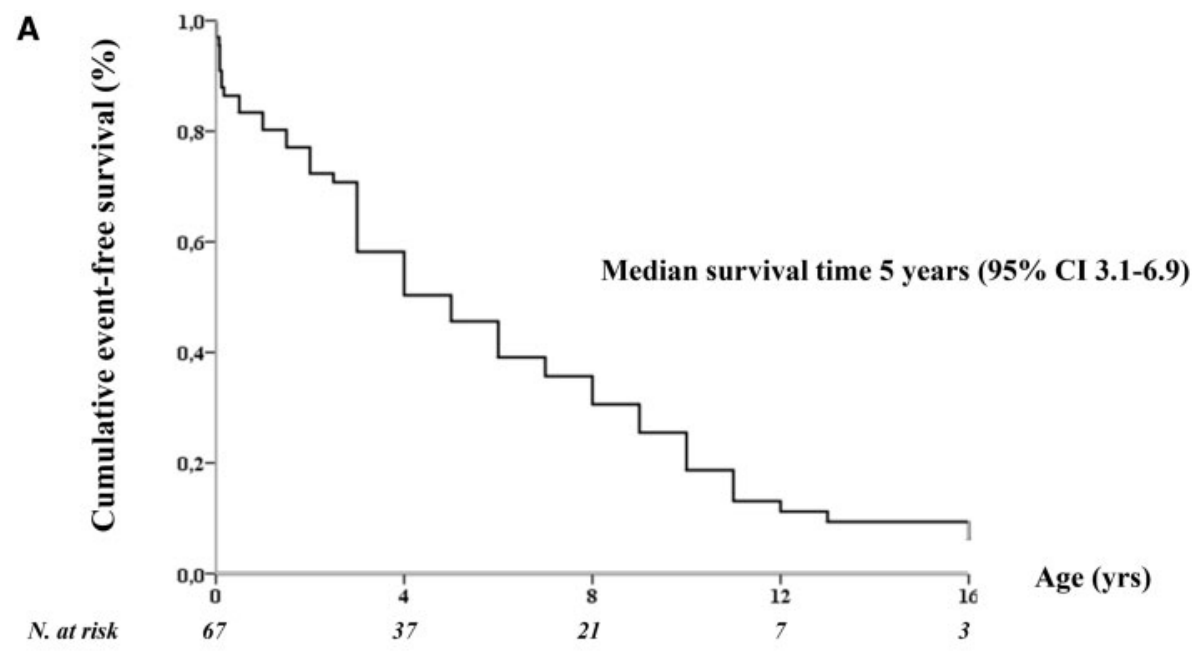

B
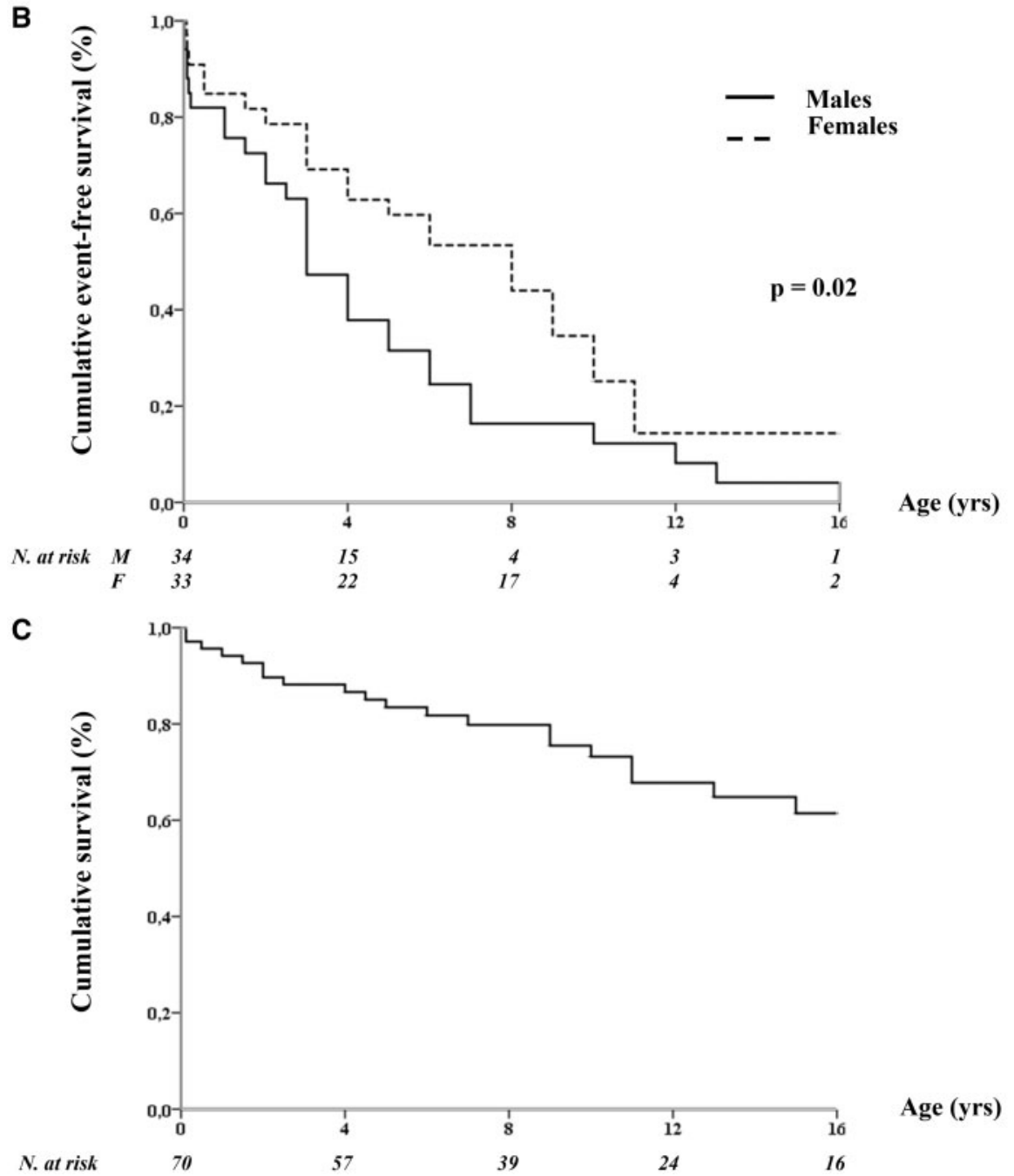

Age (yrs)

Figure 2 Event-free survival (to any first event) in the entire study population (A) and according to gender (B); cumulative survival (to sudden cardiac death) in the entire study population (C). 
Table 2 Clinical and genetic characteristics of the two most prevalent CaM-associated phenotypes

\begin{tabular}{|c|c|c|c|}
\hline & CALM-LQTS & CALM-CPVT & $P$-value \\
\hline Patients, $n$ & 36 & 21 & \\
\hline European, $n(\%)$ & $16(46)$ & $16(76)$ & 0.03 \\
\hline Proband, $n(\%)$ & $32(89)$ & $9(43)$ & $<0.001$ \\
\hline Males, $n(\%)$ & $21(58)$ & $11(52)$ & 0.78 \\
\hline $\mathrm{QTc}(\mathrm{ms})$, mean $\pm \mathrm{SD}$ & $594 \pm 73$ & $422 \pm 35$ & $<0.001$ \\
\hline Symptoms, $n(\%)$ & $29(81)$ & $21(100)$ & 0.04 \\
\hline $\mathrm{MAE}, n(\%)$ & 28 (78); 10 SCD & 10 (48); 3 SCD & 0.04 \\
\hline Median age at onset (years), median (IQR) & $1.5(0.1-5.5)$ & $6.0(3.0-8.5)$ & 0.005 \\
\hline Perinatal presentation, $n(\%)$ & $21(58)$ & $1(5)$ & $<0.001$ \\
\hline Structural cardiac comorbidities, n (\%) & $13 / 32(41)$ & $3 / 20(15)$ & 0.07 \\
\hline Treatment, $n^{\mathrm{a}}$ & 31 & 14 & \\
\hline$\beta$-blockers & $31(100)$ & $14(100)$ & \\
\hline Sodium channel blockers & $16(52)$ & $3(21)$ & 0.10 \\
\hline Cardiac sympathetic denervation & $3(10)$ & $1(7)$ & 1 \\
\hline Implanted devices, $n(\%)$ & 22 (71)15 ICD; 7 PM & 4 ICD (29) & 0.01 \\
\hline Events on therapy & $20(65)$ & $5(36)$ & 0.11 \\
\hline Median follow-up on therapy (years), median (IQR) & $5(2-10)$ & $7(6-20)$ & 0.07 \\
\hline SCD & $7(22)$ & $1(7)$ & 0.40 \\
\hline ICD shocks & $10(32)$ & $3(21)$ & 0.72 \\
\hline Genetics, $n^{\mathrm{b}}$ & 32 & 9 & \\
\hline Variants in CALM 1/2/3 gene, $n$ (\%) & $11 / 14 / 7(34 / 44 / 22)$ & $4 / 3 / 2(44 / 33 / 22)$ & 0.83 \\
\hline Inter-EF hand I-II linker, $n(\%)$ & 0 & $3(33)$ & 0.001 \\
\hline EF-hand III, $n(\%)$ & $11(34)$ & $5(56)$ & \\
\hline EF-hand IV, $n(\%)$ & $17(53)$ & $1(11)$ & \\
\hline C-terminal region, $n(\%)$ & $4(13)$ & 0 & \\
\hline De novo variant, $n(\%)$ & $27 / 29(93)^{c}$ & 7 (78) & 0.23 \\
\hline
\end{tabular}

attempts (Table 2). Over a median 5-year follow-up on therapy, at least one breakthrough event occurred in 25 (20 CALM-LQTS, 5 CALMCPVT) of these 45 patients (56\%), including eight SCD (seven in CALM-LQTS.) Four subjects underwent LCSD, followed once by right cardiac sympathetic denervation; arrhythmias recurred in all three CALM-LQTS patients undergoing denervation surgery and with an adequate follow-up; however, they are all still alive. Twelve of the 26 patients with a device (7 PM, 19 ICD) were implanted in the first year of life (Table 2). During a median post-ICD observation time of 5 (IQR 3-9) years, 10 CALM-LQTS and 3 CALM-CPVT patients received at least one appropriate ICD shock (range 1-14 shocks). The effect of mexiletine could be assessed in 11 CALM-LQTS patients, and among them arrhythmia suppression was reported in 4 (36\%). The only CALM-CPVT patient who received mexiletine together with $\beta$-blockers became asymptomatic. Verapamil was used in three patients but was discontinued in two because of VF recurrences $(n=1)$ or intolerance $(n=1)$.

\section{Discussion}

The present report provides the first comprehensive assessment of what is currently known regarding the clinical manifestations of pathogenic and likely pathogenic variants in the genes encoding calmodulin. Only very recently has it become evident that genetic perturbations in CALM1, CALM2 and CALM3 are associated with the occurrence of life-threatening cardiac arrhythmias during infancy or early in childhood. ${ }^{1}$ The availability of a mere handful of anecdotal reports of what are now referred to as calmodulinopathies has limited the understanding of the natural history, clinical diagnostic features, and clues for effective management of this rare and quite severe syndrome.

As it was done 40 years ago for LQTS, ${ }^{15-17}$ the creation of an International Calmodulinopathy Registry including most cases of this rare but potentially lethal syndrome appeared the best way to address these pressing clinical questions and to provide the critical mass of data needed to draw meaningful conclusions. This was accomplished by establishing the International Calmodulinopathy Registry. Here, we report the first findings and discuss their implications.

Calmodulin is a ubiquitously expressed protein. In the heart, CaM is a critical modulator of several ion channels such as the L-type calcium channel, the sodium channel, different potassium channels, and the ryanodine receptor. ${ }^{27}$ Unique to biology, and underscoring its importance, the entire amino acid identity of the CaM protein is derived from the transcription/translation of three distinct CALM genes 
A

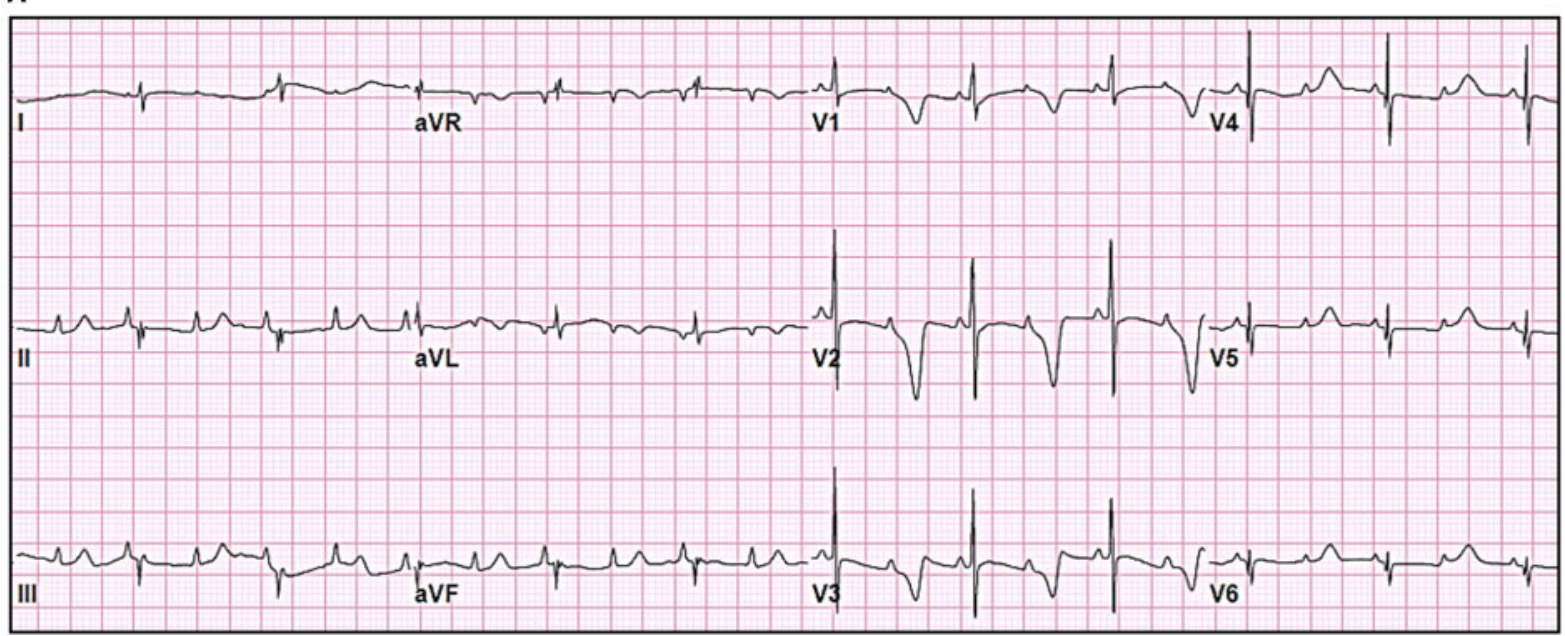

B
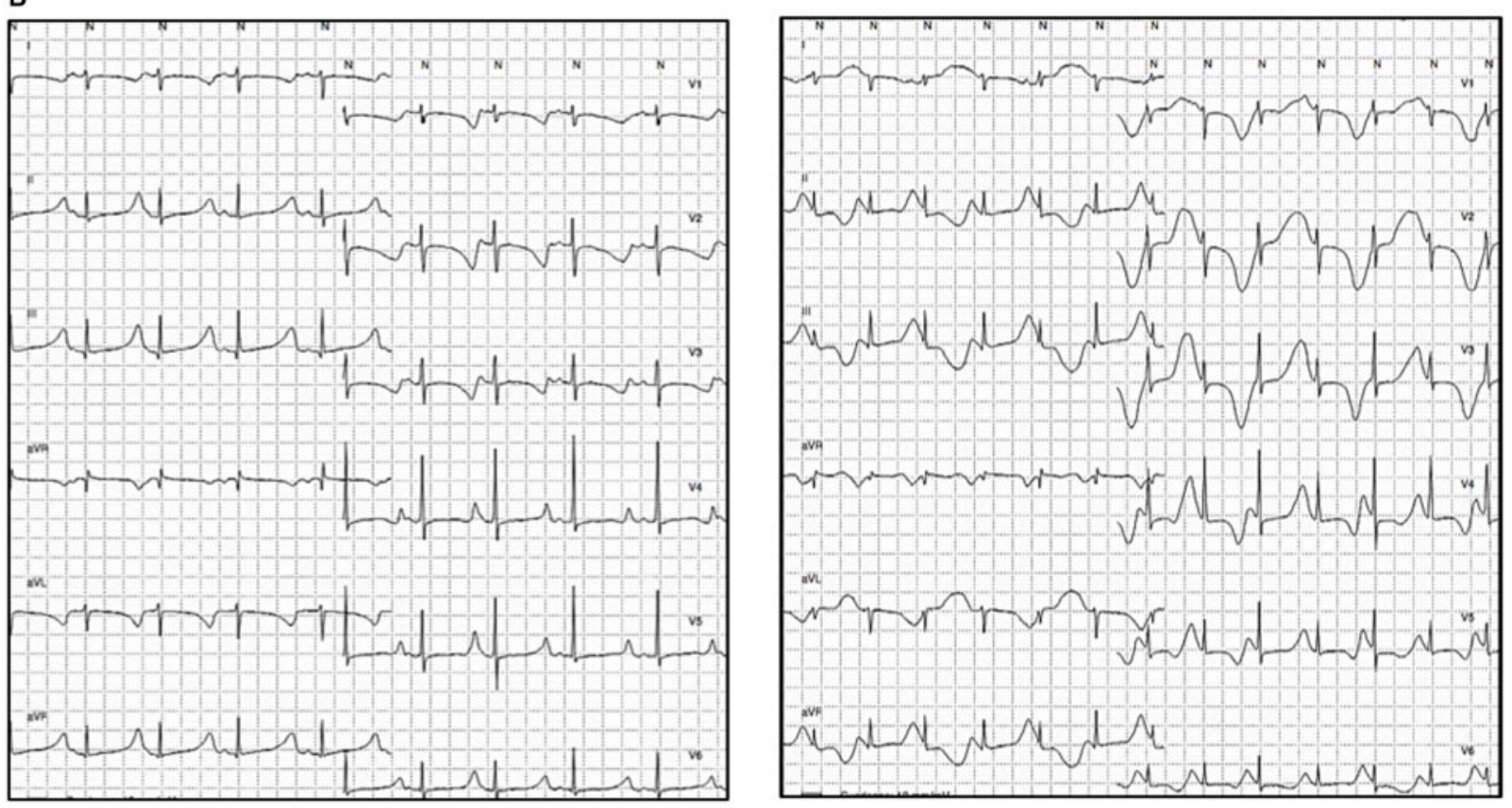

c

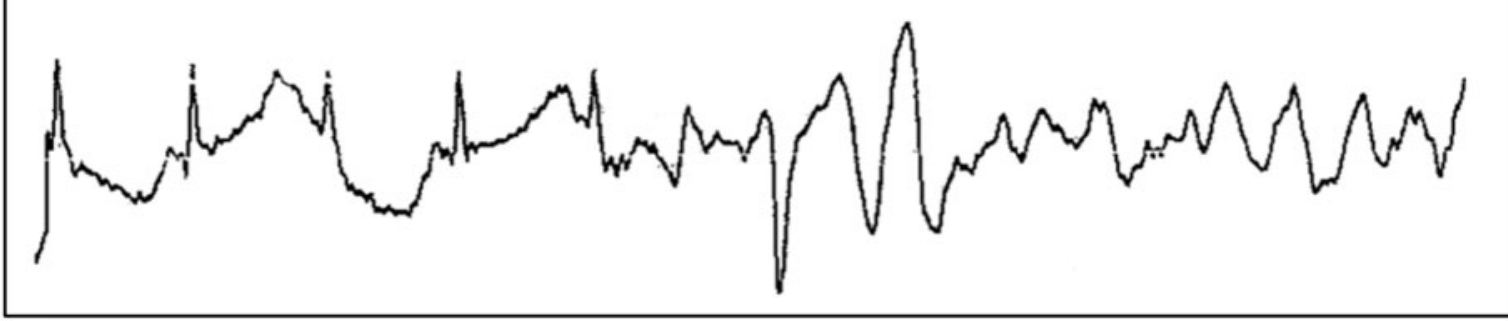

Figure 3 Representative electrocardiograms of CALM-LQTS patients. (A) CALM3-D130G, male, 4 days, 12-lead electrocardiogram showing markedly prolonged QTc and 2:1 atrioventricular block. (B) CALM 1-D130G, female, 2 years, Holter recording showing markedly prolonged QTc and phases of T wave alternans. (C) Holter electrocardiogram showing the ventricular fibrillation onset in a CALM1-D130G, female, 9 months. 


\section{INTERNATIONAL CALMODULINOPATHY REGISTRY}

\section{4 patients}

\section{Genetics}

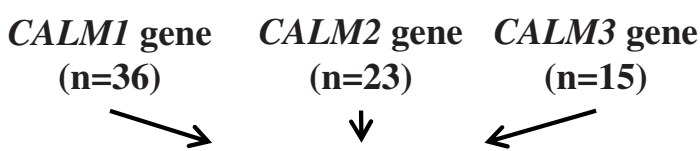

Mutations mostly located in EF-hands III and IV (80\%)
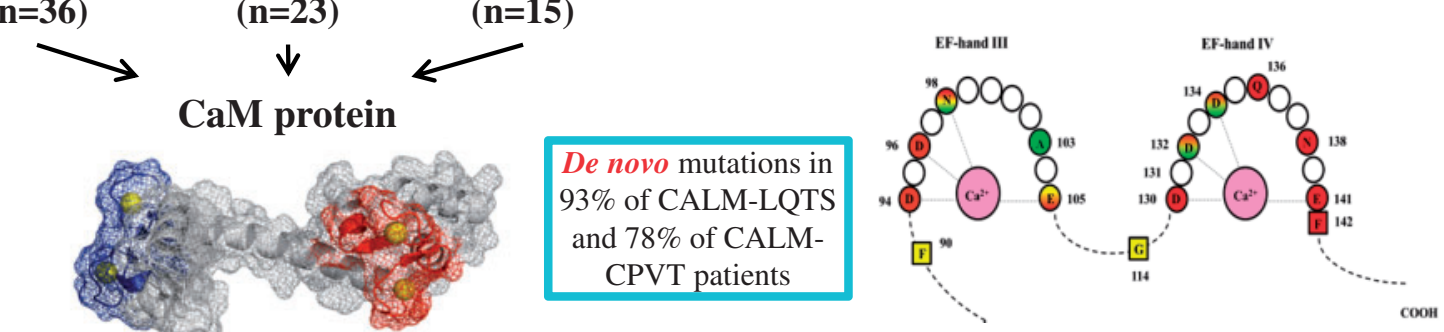

\section{Clinical hallmarks}

- Extremely rare and severe

- Median age at first cardiac event 4 years

- Trigger for arrhythmic events: adrenergic stimuli in $81 \%$ of patients

- Major arrhythmic events in $68 \%$ of patients

- Sudden cardiac death in $27 \%$

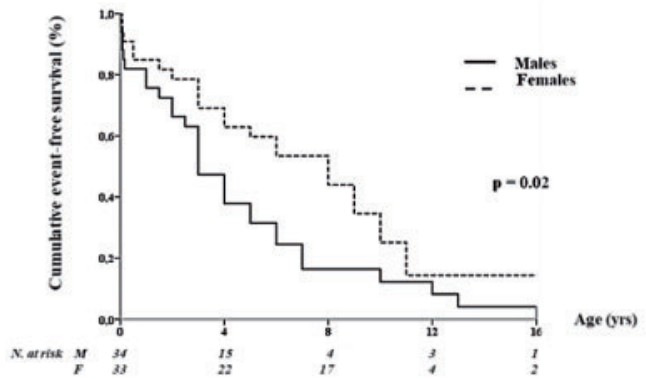

\section{PREVALENT PHENOTYPES}

CALM-LQTS (49\%)

- Mean QTc 594 $\pm 73 \mathrm{~ms}$

- Late onset peaked T-waves

- Perinatal presentation in $58 \%$

- Median age of onset 1.5 years

- Life-threatening arrhythmias in $78 \%$
CALM- CPVT (28\%)

- All symptomatic for cardiac events $48 \%$ with major arrhythmic events

- Median age of onset 6.0 years

Take home figure Clinical hallmarks and major genetic findings in patients enrolled in the International Calmodulinopathy Registry. 
residing on three different chromosomes. In addition, the CaM protein sequence is extraordinarily conserved across vertebrates and highly across all eukaryotes. ${ }^{28}$ Only recently pathogenic variants involving these three calmodulin genes (CALM1, CALM2, and CALM3), have been identified and associated to severe forms of LQTS, CPVT, ${ }^{2}$ IVF, ${ }^{3}$ and SUD.?

\section{Distinct clinical features of calmodulinopathy}

Long QT syndrome is the most common and most malignant arrhythmogenic phenotype associated to disease-causative variants in the CALM genes. In $58 \%$ of the cases, a perinatal presentation with a mean QTc >600 ms, 2:1 functional atrioventricular block, T-wave alternans, ${ }^{25}$ and/or MAEs was observed. These were all heterozygous missense variants, mainly de novo, which is not surprising given their malignancy; much less frequently they were inherited from an unaffected parent with germline mosaicism. LQTS-associated mutations were most often located in calcium binding sites at EF-hands III and IV, with a few recurrent variants (p. Asn98Ser, p.Asp130Gly, and p.Phe142Leu).

The clinical manifestations were strikingly similar independently of the ethnicities represented in our cohort. The functional effect of these CaM perturbations is probably so strong to override any influence on the phenotype by the genetic background. In addition to the severe phenotype and the early occurrence of clinical manifestations, CALM-LQTS had some specific features. The trigger of cardiac events was mainly adrenergic stimulation, and when the onset of the arrhythmias was recorded, a rapid VT, not preceded by a pause and quickly degenerating into ventricular fibrillation, was observed.

A distinctive feature of CALM-LQTS was an ECG pattern characterized by a late onset peaked $T$ wave, resembling the ECG features observed in Timothy Syndrome and in LQT3. However, at variance with LQT3, ${ }^{24}$ mexiletine did not shorten the QTc in most calmodulin cases despite reducing arrhythmic events in almost $40 \%$ of the patients. There were some similarities between CALM-LQTS and Timothy Syndrome (TS), the other calcium-related variant of LQTS, ${ }^{29}$ such as the presence of cardiac structural abnormalities and/ or neurological features and hypoglycaemia as a possible cause of death. $^{30}$

Catecholaminergic polymorphic ventricular tachycardia is the second most represented calmodulinopathy phenotype. Here too, the disease-causative variants were heterozygous missense variants, occurring in any of the three CALM genes. At variance with CALMLQTS, there were true familial cases of CALM-CPVT, although the majority of the probands $(7 / 9,78 \%)$ had de novo mutations. Symptoms were present in all affected subjects; however, compared with the LQTS phenotype, the clinical manifestations were somewhat less severe, with rare perinatal presentation and with fewer structural cardiac and neurological abnormalities. The baseline ECG is either completely normal or shows prominent $U$ waves. In most cases, the clinical manifestations were not completely typical of CPVT. Indeed, exercise and adrenergic stimulation induced ventricular ectopic beats, also polymorphic, but sometimes only isolated; bidirectional VTs was seldom reported.

Eighteen patients (27\%) showed co-existing cardiac structural abnormalities, mostly represented by atrial and ventricular septal defects. As these are the most common congenital cardiac malformations, it is likely that early detection occurred as a result of the extensive diagnostic evaluation performed in these very young patients with a severe clinical phenotype. However, the prevalence of these cardiac malformations in calmodulinopathy is apparently not trivial, compared with their general prevalence of approximately $1 \%$ of live births. ${ }^{31}$ These observations, along with the reported neurological and neurodevelopmental deficits, either subsequent or independent of prior cardiac arrest, raise the possibility that calmodulinopathy could be syndromic in a number of cases.

\section{From genotype to phenotype}

Among the 25 distinct missense variants identified, 11 have been functionally characterized in different cellular settings (heterologous expression systems, mammalian ventricular myocytes, cardiomyocytes differentiated from human induced pluripotent stem cells, hiPSC-CMs) and are summarized in Supplementary material online, Table S4. In our original description of CALM-LQTS, ${ }^{1}$ we provided evidence that $\mathrm{CaM}$ mutations exhibited reduced $\mathrm{Ca}^{2+}$-binding affinity and impaired $\mathrm{Ca}^{2+}$-mediated signal transduction. Reduced $\mathrm{Ca}^{2+}$ binding capacity was demonstrated for other LQTS-related CaM mutations. ${ }^{4,6}$ The mechanism by which this leads to prolongation of action potential duration is an impairment of $\mathrm{Ca}^{2+}$-dependent inactivation (CDI) of the L-type $\mathrm{Ca}^{2+}$ channel Cav1.2, ${ }^{6,32}$ while the other ion channels regulated by CaM are less consistently affected.

Most functional studies thus far performed, attempted to assess CaM mutation effects in heterologous expression systems or mammalian cardiomyocytes. Although these experiments contributed to delineating the underlying calmodulinopathy mechanism, their results were significantly limited by not having employed a physiologically reliable experimental platform accounting for the native stoichiometric ratio of $\mathrm{CaM}$. Since $\mathrm{CaM}$ is encoded by three different genes, i.e. six alleles, a single mutation of one allele implies that mutant $\mathrm{CaM}$ and wild-type CaMs co-exist in the cell in a 1:5 ratio.

To overcome this issue and to provide a deeper understanding of the effects conferred by CaM mutations in their native CM environment, we generated patient-specific induced pluripotent stem cells (iPSC) from skin fibroblasts of one of our patients with CALM-LQTS (p.Phe142Leu in CALM1) ${ }^{1}$ and differentiated them into $\mathrm{CMs}^{33}$ (iPSCCMs). By performing extracellular field potential, membrane action potential, and intracellular $\mathrm{Ca}^{2+}$ measurements, we demonstrated a strong dominant-negative reduction in the $\mathrm{CDI}$ of $\mathrm{Ca}_{\vee} 1.2$, resulting in increased inward $\mathrm{I}_{\mathrm{CaL}}$ and repolarization delay as the variant's predominant effect. ${ }^{33}$ Similar results were obtained by two other independent studies using an iPSC-CM platform for calmodulinopathy modelling. ${ }^{34,35}$

Catecholaminergic polymorphic ventricular tachycardia-associated disease-causative CALM variants have been studied less extensively and never in the context of patient-derived iPSC-CMs; however, the major in vitro effect of these variants is a higher binding affinity for RyR2 producing a greater RyR2 channel open probability with spontaneous formation of $\mathrm{Ca}^{2+}$ waves. ${ }^{10,32,36,37}$

Overall, these studies have provided insights into the pathophysiological mechanisms underlying life-threatening arrhythmias in the context of calmodulinopathy.

At this time, it is evident that no gene-specific phenotypic correlations can be made since mutations in all three CALM genes may give 
rise to different phenotypes. On the other hand, a few mutationspecific phenotypic correlations seem to emerge, such as the p.Asp130Gly and p.Phe142Leu mutations always associated with an LQTS phenotype. Another emerging correlation is that of mutation topology and phenotype. In fact, CALM-LQTS mutations seem to mainly affect amino acids residing in the $\mathrm{Ca}^{2+}$ binding loops (EF-hands III and IV). Functional characterization of several LQTS-associated $\mathrm{CaM}$ mutations has indeed shown that they mostly affect CaM's $\mathrm{Ca}^{2+}$ binding affinity, with a consequent impairment of the $\mathrm{Ca}^{2+}$-dependent inactivation of the $\mathrm{Ca}^{2+}$ channel. ${ }^{32-35,37-39}$ This is an established calmodulinopathy mechanism and is in accordance with the fact that the most frequently encountered phenotype across all mutations in all three genes is LQTS.

Conversely, CPVT-associated CaM mutations only occasionally involve amino acids directly responsible of $\mathrm{Ca}^{2+}$ binding. Their few functional studies suggest that they strengthen CaM's affinity for the RyR2 channel, promoting its open conformation and increasing the frequency of $\mathrm{Ca}^{2+}$ waves.

The p.Asn98Ser variant, associated with both a CPVT and LQTS phenotype, has shown multiple effects in vitro as it leads to greater RyR2 single-channel open probability ${ }^{36}$ as well as to impaired $\mathrm{CDI},{ }^{34,37}$ which fits with the two phenotypes observed in vivo. As with other arrhythmogenic diseases of genetic origin, only detailed functional studies on a case-by-case basis may explain how each specific mutation may give rise to more than one phenotype.

\section{Management}

Despite the strength of the adrenergic triggers observed in both CALM-LQTS and CALM-CPVT, it is disappointing and rather surprising that anti-adrenergic strategies effectively used in conventional LQTS and CPVT ( $\beta$-blocker therapy and LCSD) are inadequately protective for patients with calmodulinopathy. ${ }^{23}$ Indeed, $\beta$-blocker therapy, the mainstay treatment for $\mathrm{LQTS},{ }^{40}$ seems to offer modest benefit in controlling the life-threatening arrhythmias of calmodulinopathy. Mixed results were observed with the sodium channel blocker mexiletine, possibly because of a mutation-specific effect. ${ }^{41} \mathrm{Ca}^{2+}$ channel blockade may seem a rational therapeutic strategy in CALMLQTS given that impaired CDI of Cav1.2 is a prominent underlying mechanism. ${ }^{33-35}$ Unfortunately, at this time, the data available with verapamil are too limited to draw any conclusion. ${ }^{1,42}$ As part of this largely negative picture, also LCSD, the other major pillar in LQTS $^{40,43,44}$ and CPVT ${ }^{45}$ treatment, failed to prevent life-threatening arrhythmias in few CALM-LQTS patients.

Whether or not to implant an ICD in these young patients is a difficult decision, as exemplified by the following two cases. The decision not to implant an ICD in an asymptomatic infant, with a CALM2 mutation and a QTc of $552 \mathrm{~ms}$, resulted in his SCD due to documented $V F$ at age of 20 months despite full dose $\beta$-blockade. In contrast, the decision to implant an ICD in a CALM3 neonate contributed to his death due to device-related complications. These tragic examples highlight the urgent need to identify appropriate management strategies and therapies for life-threatening calmodulinopathies. ${ }^{35}$

Overall, it is difficult to provide more granular information on response to therapy because in most cases, given the lack of protection and the dramatic situations with these small children, one therapy was added or substituted to another in relatively rapid sequence which makes hazardous to provide an accurate and non-misleading picture. Not infrequently, therapies followed by early recurrences were associated subsequently with a stabilization of the condition. This is why we regard as more correct to provide our overall sense of the therapeutic outcome as we have gathered from the detailed series of events in the individual cases. Indeed, the Registry data do not as yet allow the identification of a promising approach to an effective clinical management. What appear as legitimate conclusions are that: (i) monotherapy with $\beta$-blockers is usually insufficient; (ii) combination therapy with $\beta$-blockers, sodium channel blockers and LCSD may not be sufficient, particularly in CALM-LQTS with perinatal presentation; and (iii) ICDs are probably necessary in most patients but, in the very young ones, they represent a double-edged sword and the appropriate time for implantation should be carefully balanced considering symptoms and age. Only for truly desperate cases, cardiac transplantation could be considered as a last resort treatment option. ${ }^{46}$

\section{Limitations}

All Registry data on rare and life-threatening conditions unavoidably suffer from the same limitation: namely, that despite careful and systematic collection of all possible information, the very nature of the individual management of these high risk children usually results in a series, even large, of anecdotal cases. This complicates the attempt to generalize the results, as it would be necessary and it is why we thought more correct to provide our gestalt view. More granular data, greater numbers, and longer follow-up will be necessary to define the efficacy of specific therapies or of their combination.

\section{Conclusion}

This first report from the International Calmodulinopathy Registry provides novel information on the natural history and clinical presentation of these life threatening disorders. The presence of distinct genotype-phenotype correlations is beginning to emerge. As to the response to the conventional therapies used for LQTS and CPVT, the current data are not encouraging but a longer follow-up is necessary. The future inclusion in the Registry of many more cases will provide more insights and better guidance for the best management of these patients.

\section{Supplementary material}

Supplementary material is available at European Heart Journal online.

\section{Acknowledgements}

We wish to thank Drs Mette Nyegaard, Bettina Cuneo, and Kristina Haugaa for their collaboration and Pinuccia De Tomasi for expert editorial support. A special thanks to all the families represented in this Registry.

\section{Funding}

Z.A.B. was funded by a grant (29283) from Swiss Heart Foundation C.R.B. and A.A.M.W. acknowledge the support from the Dutch Heart Foundation (CVON PREDICT project). L.C. acknowledge the support of 2017-ATE-0082 funding. The Registry has been partially funded by ERN GUARD-Heart. Partial funding for this work was provided by NIH grant 
HL083374 (A.L.G., P.J.S., L.C.) and HL131914 (A.L.G.). D.J.T. and M.J.A. acknowledge the support from the Mayo Clinic Windland Smith Rice Comprehensive Sudden Cardiac Death Program. L.C. and P.J.S. acknowledge the support of the Leducq Foundation for Cardiovascular Research grant 18CVD05 "Towards Precision Medicine with Human iPSCs for Cardiac Channelopathies".

Conflict of interest: M.J.A. is a consultant for Audentes Therapeutics, Boston Scientific, Gilead Sciences, Invitae, Medtronic, MyoKardia, and St. Jude Medical. M.J.A. and Mayo Clinic have an equity/royalty relationship (without remuneration so far) with AliveCor, Blue Ox Health Corporation, and StemoniX. M.V. receives salary/stock from Invitae Corporation. H.H.O. have received salary from Abbott and have research partnership with Medtronic. However, none of the disclosures pertain directly to this paper and none of the companies provided financial support for this study. All other authors declared no conflict ofinterest.

\section{References}

1. Crotti L, Johnson CN, Graf E, De Ferrari GM, Cuneo BF, Ovadia M, Papagiannis J, Feldkamp MD, Rathi SG, Kunic JD, Pedrazzini M, Wieland T, Lichtner P, Beckmann BM, Clark T, Shaffer C, Benson DW, Kääb S, Meitinger T, Strom TM, Chazin WJ, Schwartz PJ, George AL. Calmodulin mutations associated with recurrent cardiac arrest in infants. Circulation 2013;127:1009-1017.

2. Nyegaard M, Overgaard MT, Søndergaard MT, Vranas M, Behr ER, Hildebrandt LL, Lund J, Hedley PL, Camm AJ, Wettrell G, Fosdal I, Christiansen M, Børglum AD. Mutations in calmodulin cause ventricular tachycardia and sudden cardiac death. Am J Hum Genet 2012;91:703-712.

3. Marsman RF, Barc J, Beekman L, Alders M, Dooijes D, Van Den Wijngaard A, Ratbi I, Sefiani A, Bhuiyan ZA, Wilde AAM, Bezzina CR. A mutation in CALM1 encoding calmodulin in familial idiopathic ventricular fibrillation in childhood and adolescence. J Am Coll Cardiol 2014;63:259-266.

4. Makita N, Yagihara N, Crotti L, Johnson CN, Beckmann B-M, Roh MS, Shigemizu D, Lichtner P, Ishikawa T, Aiba T, Homfray T, Behr ER, Klug D, Denjoy I, Mastantuono E, Theisen D, Tsunoda T, Satake W, Toda T, Nakagawa H, Tsuji Y, Tsuchiya T, Yamamoto H, Miyamoto Y, Endo N, Kimura A, Ozaki K, Motomura H, Suda K, Tanaka T, Schwartz PJ, Meitinger T, Kääb S, Guicheney P, Shimizu W, Bhuiyan ZA, Watanabe H, Chazin WJ, George AL. Novel calmodulin mutations associated with congenital arrhythmia susceptibility. Circ Cardiovasc Genet 2014;7: $466-474$.

5. Reed GJ, Boczek NJ, Etheridge SP, Ackerman MJ. CALM3 mutation associated with long QT syndrome. Heart Rhythm 2015;12:419-422.

6. Pipilas DC, Johnson CN, Webster G, Schlaepfer J, Fellmann F, Sekarski N, Wren LM, Ogorodnik KV, Chazin DM, Chazin WJ, Crotti L, Bhuiyan ZA, George AL. Novel calmodulin mutations associated with congenital long QT syndrome affect calcium current in human cardiomyocytes. Heart Rhythm 2016;13:2012-2019.

7. Chaix MA, Koopmann TT, Goyette P, Alikashani A, Latour F, Fatah M, Hamilton RM, Rioux JD. Novel CALM3 mutations in pediatric long QT syndrome patients support a CALM3-specific calmodulinopathy. Hear Case Reports 2016;2:250-254.

8. Boczek NJ, Gomez-Hurtado N, Ye D, Calvert ML, Tester DJ, Kryshtal DO, Hwang HS, Johnson CN, Chazin WJ, Loporcaro CG, Shah M, Papez AL, Lau YR, Kanter R, Knollmann BC, Ackerman MJ. Spectrum and prevalence of CALM1-, CALM2-, and CALM3-encoded calmodulin variants in long QT syndrome and functional characterization of a novel long QT syndrome-associated calmodulin missense variant, E141G. Circ Cardiovasc Genet 2016;9:136-146.

9. Anderson JH, Tester DJ, Will ML, Ackerman MJ. Whole-exome molecular autopsy after exertion-related sudden unexplained death in the young. Circ Cardiovasc Genet 2016;9:259-265.

10. Gomez-Hurtado N, Boczek NJ, Kryshtal DO, Johnson CN, Sun J, Nitu FR, Cornea RL, Chazin WJ, Calvert ML, Tester DJ, Ackerman MJ, Knollmann BC. Novel CPVT-associated calmodulin mutation in CALM3 (CALM3-A103V) activates arrhythmogenic Ca waves and sparks. Circ Arrhythmia Electrophysiol 2016;9: e004161.

11. Jiménez-Jáimez J, Doza JP, Ortega Á, Macías-Ruiz R, Perin F, Rodríguez-Vázquez Del Rey MM, Ortiz-Genga M, Monserrat L, Barriales-Villa R, Blanca E, Álvarez M, Tercedor L. Calmodulin 2 mutation N98S is associated with unexplained cardiac arrest in infants due to low clinical penetrance electrical disorders. PLoS One 2016;11:1-10.

12. Takahashi K, Ishikawa T, Makita N, Takefuta K, Nabeshima T, Nakayashiro M. A novel de novo calmodulin mutation in a 6-year-old boy who experienced an aborted cardiac arrest. HeartRhythm Case Rep 2017;3:69-72.
13. Daly A, Johnson NM, Decker E, Callis TE, Tahiliani J, Garcia J, Aguilar S, Murillo L, Herrera B, Beltran D, Harte R, Dunn K, Dubin AM, Ceresnak SR, Priest J, Motonaga KS, Vatta M. Pathogenic variants in calmodulin associated with resuscitated childhood cardiac arrest (Abstract C-AB01-05. ). Heart Rhythm 2017;14:S2.

14. George AL. Calmodulinopathy: a genetic trilogy. Heart Rhythm 2015;12:423-424.

15. Schwartz PJ. The idiopathic long QT syndrome: the need for a prospective registry. Eur Heart J 1983;4:529-531.

16. Moss AJ, Schwartz PJ, Crampton RS, Locati E, Carleen E. The long QT syndrome: a prospective international study. Circulation 1985;71:17-21.

17. Moss A, Schwartz PJ. 25th Anniversary of the International Long-QT Syndrome Registry: an ongoing quest to uncover the secrets of long-QT syndrome. Circulation 2005;111:1199-1201.

18. den Dunnen J, Dalgleish R, Maglott D, Hart R, Greenblatt M, McGowan J, Roux A, Smith T, Antonarakis S, Taschner P. HGVS recommendations for the description of sequence variants: 2016 update. Hum Mutat 2016;37:564-569.

19. Richards S, Aziz N, Bale S, Bick D, Das S, Gastier-Foster J, Grody W, Hegde M, Lyon E, Spector E, Voelkerding K, Rehm H, Committee A. Standards and guidelines for the interpretation of sequence variants: a joint consensus recommendation of the American College of Medical Genetics and Genomics and the Association for Molecular Pathology. Genet Med 2015;17:405-424.

20. Consortium 1000 Genomes Project, Auton A, Brooks L, Durbin R, Garrison E, Kang H, Korbel J, Marchini J, McCarthy S, McVean G, Abecasis G. A global reference for human genetic variation. Nature 2015;526:68-74.

21. Exome Variant Server, NHLBI GO Exome Sequencing Project (ESP), Seattle, WA. http://evs.gs.washington.edu/EVS/ (April 2018).

22. Lek M, Karczewski KJ, Minikel EV, Samocha KE, Banks E, Fennell T, O'DonnellLuria AH, Ware JS, Hill AJ, Cummings BB, Tukiainen T, Birnbaum DP, Kosmicki JA, Duncan LE, Estrada K, Zhao F, Zou J, Pierce-Hoffman E, Berghout J, Cooper DN, Deflaux N, DePristo M, Do R, Flannick J, Fromer M, Gauthier L, Goldstein J, Gupta N, Howrigan D, Kiezun A, Kurki MI, Moonshine AL, Natarajan P, Orozco L, Peloso GM, Poplin R, Rivas MA, Ruano-Rubio V, Rose SA, Ruderfer DM, Shakir K, Stenson PD, Stevens C, Thomas BP, Tiao G, Tusie-Luna MT, Weisburd B, Won H-H, Yu D, Altshuler DM, Ardissino D, Boehnke M, Danesh J, Donnelly S, Elosua R, Florez JC, Gabriel SB, Getz G, Glatt SJ, Hultman CM, Kathiresan S, Laakso M, McCarroll S, McCarthy MI, McGovern D, McPherson R, Neale BM, Palotie A, Purcell SM, Saleheen D, Scharf JM, Sklar P, Sullivan PF, Tuomilehto J, Tsuang MT, Watkins HC, Wilson JG, Daly MJ, MacArthur DG. Analysis of protein-coding genetic variation in 60,706 humans. Nature 2016;536:285-291.

23. Priori SG, Wilde AA, Horie M, Cho Y, Behr ER, Berul C, Blom N, Brugada J, Chiang C-E, Huikuri H, Kannankeril P, Krahn A, Leenhardt A, Moss A, Schwartz PJ, Shimizu W, Tomaselli G, Tracy C, Document Reviewers, Ackerman M, Belhassen B, Estes NAM, Fatkin D, Kalman J, Kaufman E, Kirchhof P, SchulzeBahr E, Wolpert C, Vohra J, Refaat M, Etheridge SP, Campbell RM, Martin ET, Quek SC; Heart Rhythm Society; European Heart Rhythm Association; Asia Pacific Heart Rhythm Society. Executive summary: HRS/EHRA/APHRS expert consensus statement on the diagnosis and management of patients with inherited primary arrhythmia syndromes. Europace 2013;15:1389-1406.

24. Priori SG, Wilde AA, Horie M, Cho Y, Behr ER, Berul C, Blom N, Brugada J, Chiang C-E, Huikuri H, Kannankeril P, Krahn A, Leenhardt A, Moss A, Schwartz PJ, Shimizu W, Tomaselli G, Tracy C. Executive summary: HRS/EHRA/APHRS expert consensus statement on the diagnosis and management of patients with inherited primary arrhythmia syndromes. Heart Rhythm 2013;10:e85-108.

25. Schwartz PJ, Priori SG, Locati EH, Napolitano C, Cantù F, Towbin JA, Keating MT, Hammoude H, Brown AM, Chen LS, Colatsky TJ. Long QT syndrome patients with mutations of the SCN5A and HERG genes have differential responses to $\mathrm{Na}+$ channel blockade and to increases in heart rate. Implications for gene-specific therapy. Circulation 1995;92:3381-3386.

26. Zhang L, Benson DW, Tristani-Firouzi M, Ptacek LJ, Tawil R, Schwartz PJ, George AL, Horie M, Andelfinger G, Snow GL, Fu YH, Ackerman MJ, Vincent GM. Electrocardiographic features in Andersen-Tawil syndrome patients with KCNJ2 mutations: characteristic T-U-wave patterns predict the KCNJ2 genotype. Circulation 2005;111:2720-2726.

27. Ben-Johny M, Dick IE, Sang L, Limpitikul WB, Kang PW, Niu J, Banerjee R, Yang W, Babich JS, Issa JB, Lee SR, Namkung H, Li J, Zhang M, Yang PS, Bazzazi H, Adams PJ, Joshi-Mukherjee R, Yue DN, Yue DT. Towards a unified theory of calmodulin regulation (calmodulation) of voltage-gated calcium and sodium channels. Curr Mol Pharmacol 2015;8:188-205.

28. Halling DB, Liebeskind BJ, Hall AW, Aldrich RW. Conserved properties of individual $\mathrm{Ca}^{2+}$-binding sites in calmodulin. Proc Natl Acad Sci USA 2016;113: E1216-E1225.

29. Splawski I, Timothy KW, Sharpe LM, Decher N, Kumar P, Bloise R, Napolitano C, Schwartz PJ, Joseph RM, Condouris K, Tager-Flusberg H, Priori SG, Sanguinetti MC, Keating MT. $\mathrm{Ca}(\mathrm{V}) 1.2$ calcium channel dysfunction causes a multisystem disorder including arrhythmia and autism. Cell 2004;119:19-31. 
30. Dufendach KA, Timothy K, Ackerman MJ, Blevins B, Pflaumer A, Etheridge S, Perry J, Blom NA, Temple J, Chowdhury D, Skinner JR, Johnsrude C, Bratincsak A, Bos JM, Shah M. Clinical outcomes and modes of death in Timothy syndrome: a multicenter international study of a rare disorder. JACC Clin Electrophysiol 2018; 4:459-466.

31. Triedman JK, Newburger JW. Trends in congenital heart disease: the next decade. Circulation 2016;133:2716-2733.

32. Yin G, Hassan F, Haroun AR, Murphy LL, Crotti L, Schwartz PJ, George AL, Satin J. Arrhythmogenic calmodulin mutations disrupt intracellular cardiomyocyte $\mathrm{Ca}^{2+}$ regulation by distinct mechanisms. J Am Heart Assoc 2014;3:1-15.

33. Rocchetti M, Sala L, Dreizehnter L, Crotti L, Sinnecker D, Mura M, Pane LS, Altomare C, Torre E, Mostacciuolo G, Severi S, Porta A, De Ferrari GM, George AL, Schwartz PJ, Gnecchi M, Moretti A, Zaza A. Elucidating arrhythmogenic mechanisms of long-QT syndrome CALM1-F142L mutation in patient-specific induced pluripotent stem cell-derived cardiomyocytes. Cardiovasc Res 2017;113: 531-541.

34. Yamamoto $Y$, Makiyama T, Harita T, Sasaki K, Wuriyanghai $Y$, Hayano M, Nishiuchi S, Kohjitani H, Hirose S, Chen J, Yokoi F, Ishikawa T, Ohno S, Chonabayashi K, Motomura H, Yoshida Y, Horie M, Makita N, Kimura T. Allelespecific ablation rescues electrophysiological abnormalities in a human iPS cell model of long-QT syndrome with a CALM2 mutation. Hum Mol Genet 2017;26: 1670-1677.

35. Limpitikul WB, Dick IE, Tester DJ, Boczek NJ, Limphong P, Yang W, Choi MH, Babich J, DiSilvestre D, Kanter RJ, Tomaselli GF, Ackerman MJ, Yue DT. A precision medicine approach to the rescue of function on malignant calmodulinopathic long-QT syndrome. Circ Res 2017;120:39-48.

36. Hwang HS, Nitu FR, Yang Y, Walweel K, Pereira L, Johnson CN, Faggioni M, Chazin WJ, Laver D, George AL, Cornea RL, Bers DM, Knollmann BC. Divergent regulation of ryanodine receptor 2 calcium release channels by arrhythmogenic human calmodulin missense mutants. Circ Res 2014;114: 1114-1124.

37. Limpitikul WB, Dick IE, Joshi-Mukherjee R, Overgaard MT, George AL, Yue DT. Calmodulin mutations associated with long QT syndrome prevent inactivation of cardiac L-type Ca2 + currents and promote proarrhythmic behavior in ventricular myocytes. I Mol Cell Cardiol 2014;74:115-124

38. Kotta M-C, Sala L, Ghidoni A, Badone B, Ronchi C, Parati G, Zaza A, Crotti L. Calmodulinopathy: a novel, life-threatening clinical entity affecting the young. Front Cardiovasc Med 2018;5:175.

39. Badone B, Ronchi C, Kotta M-C, Sala L, Ghidoni A, Crotti L, Zaza A Calmodulinopathy: functional effects of CALM mutations and their relationship with clinical phenotypes. Front Cardiovasc Med 2018;5:1-13.

40. Schwartz PJ, Ackerman MJ. The long QT syndrome: a transatlantic clinical approach to diagnosis and therapy. Eur Heart J 2013;34:3109-3116.

41. Schwartz PJ, Sala L. Precision versus traditional medicine-clinical questions trigger progress in basic science. Circ Res 2019;124:459-461.

42. Webster G, Schoppen ZJ, George AL. Treatment of calmodulinopathy with verapamil. BMJ Case Rep 2017;2017:bcr-2017-220568.

43. Schwartz PJ, Priori SG, Cerrone M, Spazzolini C, Odero A, Napolitano C, Bloise R, De Ferrari GM, Klersy C, Moss AJ, Zareba W, Robinson JL, Hall WJ, Brink PA, Toivonen L, Epstein AE, Li C, Hu D. Left cardiac sympathetic denervation in the management of high-risk patients affected by the long-QT syndrome. Circulation 2004;109:1826-1833.

44. Collura CA, Johnson JN, Moir C, Ackerman MJ. Left cardiac sympathetic denervation for the treatment of long QT syndrome and catecholaminergic polymorphic ventricular tachycardia using video-assisted thoracic surgery. Heart Rhythm 2009;6:752-759.

45. De Ferrari GM, Dusi V, Spazzolini C, Bos JM, Abrams DJ, Berul Cl, Crotti L, Davis AM, Eldar M, Kharlap M, Khoury A, Krahn AD, Leenhardt A, Moir CR, Odero A, Olde Nordkamp L, Paul T, Rosés I Noguer F, Shkolnikova M, Till J, Wilde AAM, Ackerman MJ, Schwartz PJ. Clinical management of catecholaminergic polymorphic ventricular tachycardia: the role of left cardiac sympathetic denervation. Circulation 2015;131:2185-2193.

46. Kelle AM, Bos JM, Etheridge SP, Cannon BC, Bryant RM, Johnson JN, Ackerman MJ. Cardiac transplantation in children and adolescents with long QT syndrome. Heart Rhythm 2017;14:1182-1188. 